\title{
Gastritis Cystica Polyposa Found in an Unoperated Stomach: An Unusual Case Treated by Endoscopic Polypectomy
}

A 47-year-old man was referred to the Gastroenterology Department for investigation of a polypoid stomach mass detected incidentally at abdominal computed tomography (CT). The patient did not describe any history of gastric operation. Upper gastrointestinal endoscopy revealed a broad-based polypoid mass, approximately $25 \mathrm{~mm}$ in diameter, at the greater curvature of the corpus. The surface of the polyp was smooth and slightly bluish. Biopsies revealed normal mucosa. Endoscopic ultrasonography (EUS) showed a homogeneous, hypoechoic, and multilocular polypoid mass in the submucosa (Figure 1). After submucosal injections of 1/20 000 epinephrine-saline solution endoscopic polypectomy was successfully performed. Histological examination of the polyp demonstrated numerous cystic dilatations lined with gastric surface epithelium under the thin overlying mucosa, and a diagnosis of gastritis cystica polyposa has been established (Figure 2 ). The patient was re-admitted with hematemesis and melena, 14 days after endoscopic polypectomy. Esophagogastroduodenoscopy revealed an adherent clot at the site of the polypectomy, and an epinephrine injection was given endoscopically. There was no further rebleeding, and 6 months after the endoscopic polypectomy a repeat endoscopy showed no abnormality. GCP was first described by Littler \& Gleibermann in 1972 [1]. These lesions are usually found at gastroenterostomy sites [2]; however, they may rarely also develop in an unoperated stomach as in this patient [2,3]. It has been suggested that GCP at a gastroenterostomy site is a precancerous lesion [4]. Therefore, removal and histopathological evaluation of these lesions is necessary. Ju et al. published the first report of removal by endoscopic polypectomy of a pedunculated GCP in an unoperated stomach [3]. The second instance, presented here, differs from the first in that the GCP in this case was wide-based and sessile. Although there was no early complication due to endoscopic polypectomy, on the 14th postoperative day there was late bleeding from the polypectomy site which did not recur after epinephrine injection. In conclusion, GCP can occur in an unoperated stomach, and can be treated by endoscopic polypectomy.

\section{K. Tuncer ${ }^{1}$, M. Alkanat ${ }^{2}$, A. Musoğlu ${ }^{1}$, A. Aydın ${ }^{1}$}

${ }^{1}$ Gastroenterology Department, Ege University Medical School; İzmir, Turkey

2 Pathology Department of Ege University Medical School; İzmir, Turkey.

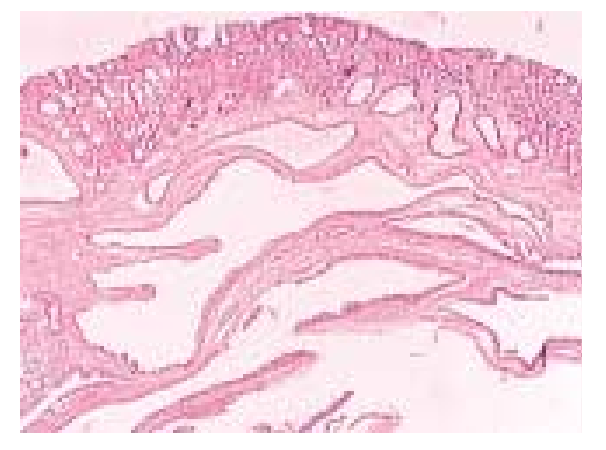

Figure 2 Histopathological examination of the polyp revealed numerous cystic dilatations lined with gastric epithelium, under the overlying mucosa (hematoxylin \& eosin;× 40).

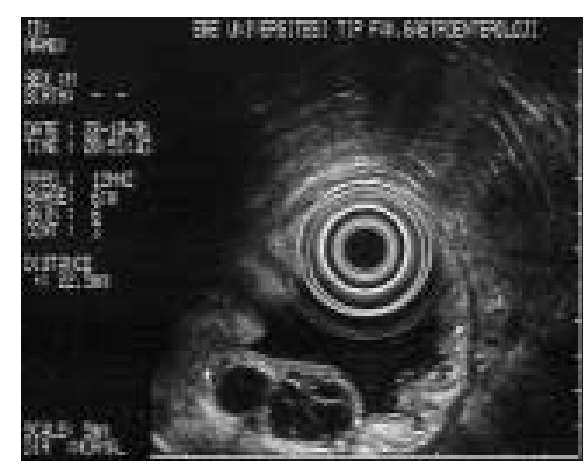

Figure 1 Endoscopic ultrasonography showed a homogeneous, hypoechoic, and multilocular polypoid mass with no solid component, in the submucosa.

\section{References}

${ }^{1}$ Littler ER, Gleibermann E. Gastritis cystica polyposa (gastric mucosal prolapse at gastroenterostomy site, with cystic and infiltrative epithelial hyperplasia).

Cancer 1972; 29: 205-209

${ }^{2}$ Wu MT, Pan HB, Lai PHet al. CT of gastritis cystica polyposa. Abdom Imaging 1994; 19: 8-10

${ }^{3}$ Ju SP, Seung JM, Hwoon YJet al. Endoscopic treatment of gastritis cystica polyposa found in unoperated stomach. Gastrointest Endosc 2001; 54: 101 - 103

${ }^{4}$ Franzin G, Musola R, Zamboni G, Manfrini C. Gastritis cystica polyposa: a possible precancerous lesion. Tumori 1985; 71: $13-18$

\section{Corresponding Author}

\section{K. Tuncer, M.D.}

Ege Üniversitesi Tıp Fakültesi Gastroenteroloji Klinigi 35100 Bornova Izmir, Turkey

Fax: $\quad$ +90-232-3881969103

E-mail: drkoray@yahoo.com 